of the impurity, is left on the blotting paper. From the results of a long series of preliminary experiments with large volumes of air, it has been possible to construct a scale of shades each representing a definite number of milligrams of impurity per cubic centimetre. The reading of the record thus consists in matching the spot against a corresponding shade in a numbered scale, an operation which can be done quite readily with sufficient accuracy. The spots are obtained in succession round the edges of the blotting paper, which is in the form of a circular disc, rotated once in twenty-four hours and controlled by clockwork.

In the earlier form of the instrument the mechanism for drawing in the air was operated by water entering a vessel provided with a syphon, which caused the water to rise and fall between two fixed levels. During the fall, air was drawn through the filter disc, an arrangement being provided for making an airtight joint between the filter nozzle and the air inlet pipe during this operation. During the rise, the filter dise was unclamped and rotated to a point fixed by the clock, the filtered air being meanwhile expelled by the rise of water in the main vessel. This form of apparatus had certain disadvantages, of which the present writer can speak feelingly as a former Superintendent of the Instruments Division of the Meteorological Office, where one of these instruments is work ing. The necessity for a continuous water supply is a serious drawback, and experience has made it obvious that improvements were necessary in other features of the instrument.

In the new design, the filtering mechanism is operated entirely by a falling weight which is wound to the top of its travel once a day. No outside source of power is required, and the installation of the instrument is thus not restricted to sites where these are available. The descending weight operates a crank through a train of gearing, and this crank is connected to a reinforced rubber bellows, so that at each revolution the bellows is expanded and contracted. On the down stroke one litre of air is drawn in very slowly through the filter disc, which is gripped meanwhile between the top of the filter nozzle and a corresponding ' nose' above the paper. On the up stroke air is expelled from the bellows, the filter nozzle being meanwhile lowered out of contact with the paper. By means of an ingenious auxiliary clamping device operated by cams, the paper can be held in the same position while air is drawn in on one, two, four, or eight successive revolutions of the crank. In this way the volume of air contributing to each spot may be varied from one to eight litres, to suit the locality and season. This feature is, in my opinion, one of the chief advantages of the new instrument.

In the jet dust counter a sample of the air to be examined is caused, by means of a pump, to pass through a narrow slit behind which is a cleaned microscope cover glass. Before entering the slit the air passes through a cylindrical 'damping chamber' lined with wet blotting paper, and the velocity in the jet is such that a fall of pressure takes place and condensation occurs as a result of the adiabatic cooling. The water droplets and dust particles strike the cover glass, the dust adheres, and the water evaporates. In this way the dust in a known volume of air is obtained in the form of a narrow ribbon-like deposit on the cover glass, which can be examined quantitatively and qualitatively under a microscope. In the older apparatus only one record could be obtained on each glass, and, as several operations are involved, it was distinctly troublesome to get a series of records, for example, in different rooms of a building. In the new instrument, which has been put on the market by Messrs. C. F. Casella and Co., Ltd., the cover glass is carried on a rotatable head which can be operated from the back of the instrument. A two-way tap also is provided, by means of which the jet can be put out of action while the damping chamber is being flushed with the new sample of air. By the aid of these devices a series of, say, eight or ten separate records can be obtained on a single cover glass, the lines of deposit intersecting at the centre like the spokes of a wheel. With a suitable eyepiece and objective in the microscope, a rough preliminary comparison of the records can be made by inspection, since portions of two or more records can be brought into the field of view simultaneously. In this way the scope of the instrument has been greatly extended and the ease of manipulation much improved. E. G. BILHAM.

\title{
Importation of Scientific Specimens and Apparatus into Great Britain.
}

$A \mathrm{~S}$ the result of a report by the Association of British Zoologists, the Council of the British Association in February 1931 appointed a committee to consider action with the view of the amelioration of the customs regulations affecting the importation of scientific specimens and apparatus. Following upon discussion between officers of the Association and the Custom House authorities, the latter have most kindly supplied the Association with a memorandum on the reliefs from customs duties on scientific instruments and cinematograph films, and from the import prohibitions on plumage likely to be of use to scientific workers, together with a note on procedure in respect of the importation of scientific specimens preserved in spirit.

The memorandum on scientific instruments and cinematograph films was supplied confidentially to enable the Association to advise bona fide scientific workers, but not for general publication, since some of the relaxations are extra-statutory and liable to modification or withdrawal as the interests of the revenue may demand. The British Association is, however, prepared to advise on specific applications from scientific workers or societies. Inquiries should be addressed to the Secretary of the British Association at Burlington House, London, W.1.
It clearly emerged in the course of discussion that some of the difficulties which have been encountered by scientific workers under the customs regulations might have been avoided by previous communication with the Board of Customs and Excise, Custom House, Lower Thames Street, London, E.C.3.

The procedure with regard to the importation of scientific specimens in spirit which will apply in future is as follows.

It will be necessary that the person by whom the specimens are imported into Great Britain (or the person or institution to whom they are addressed, in the case of specimens dispatched by a consignor abroad) should be formally authorised to receive spirits free of duty for use in an art or manufacture, under the provisions of the Finance Act, 1902, Section 8 . Where, however, the importer or consignee does not already hold such an authority, the collector of customs and excise at the port of importation will grant it, subject to the conditions in the next paragraph.

If the specimens are imported as ship's cargo, the necessary customs entry must describe them as specimens preserved in spirits, with a sufficient description of their nature and the approximate quantity of spirits, and must show the name and address of the importer or consignee. With the entry must be produced

No. 3246, VoL. 129] 
letters or other documents sufficiently establishing the status of the importer or consignee and the purposes for which the specimens are imported. The collector of customs and excise will be at liberty to request further information, if he considers it necessary. Where specimens are imported in personal baggage, similar information will be asked for.

If these requirements are satisfactorily complied with, the necessary authority will be granted forthwith and the specimens admitted immediately free of any charge of spirit duty.

It is not necessary that scientific workers proceeding on expeditions abroad should take any action before leaving Great Britain. It is, however, advisable, with the view of avoiding delay, that scientific workers returning with specimens should have the letters or other documents required to establish the facts readily available, and, in the case of specimens which are being received from senders abroad, that the forwarding agent who is entrusted with the work of clearing the goods should be supplied with the necessary information and letters, etc., in good time.

\section{University and Educational Intelligence.}

LoNDON.-The following honorary appointments to the staff of the London School of Hygiene and Tropical Medicine are announced :-Dr. James Fenton, medical officer of health for the Borough of Kensington, to be an additional lecturer on public health administration and practice; Mr. L. W. G. Malcolm, conservator of the Wellcome Historical Medical Museum, to be a lecturer on racial hygiene.

A course of nine lectures on television will be given by Mr. J. J. Denton, honorary secretary of the Television Society, at the Borough Polytechnic, Borough Road, London, S.E.1, on Thursdays at eight o'clock, commencing on Jan. 21. Further information can be obtained from the Principal of the Polytechnic.

THE finance of public elementary education as exemplified, on one hand, in certain Tyneside areas and, on the other, in a number of wealthy watering. places, forms the subject of a pamphlet entitled "The Finance of Public Elementary Education", by Mr. Ernest Dyer, issued in November by the Tyneside Council of Social Service (17 Ellison Place, Newcastleupon-Tyne). The gist of the problem discussed is indicated in the following comparison between Hebburn and Bexhill urban districts. In 1929-30 Hebburn (a Tyneside town) had 4683 elementary school children and a $1 d$. rate yielded $£ 395$ or $1 s .8 \frac{1}{4} d$. a child, so that an education rate of $3 s, 2 d$. in the $\mathfrak{f}$ was needed to finance an expenditure of $£ 8$ 19s. 9d. per child. Bexhill, with an equal population, had only 1339 elementary school children, a $1 d$. rate yielded $16 s .8 \frac{1}{2} d$. per child, and a rate of $7 \frac{1}{4} d$. in the $£$ (one-fifth of the Hebburn rate) enabled it to spend $£ 133 s$. per child (fifty per cent more than Hebburn expenditure). The following year, under the operation of the Derating Act, Hebburn's rate had to be raised from $3 s$. $2 d$. to 4s. $7 d$., while Bexbill's position remained unchanged. The conclusion drawn is that the formula under which grants-in-aid are fixed is becoming increasingly ineffective as a means of rectifying such disparities between rich and poor authorities, and there can be no satisfactory advance in education in the poorer districts, such as those of the Tyneside, until the State can be persuaded to accept a greater share of financial responsibility. The conclusion is to some extent invalidated by a number of important recent modifica. tions of the grants-in-aid rules. A summary of these is given at the end of the paper.

\section{Calendar of Geographical Exploration.}

\author{
Jan. 17, 1773.-Crossing the Antarctic Circle.
}

In the sixteenth and seventeenth centuries there was a widespread belief in the existence of a great southern world. The revival of interest in geography in the eighteenth century led the Royal Society to urge on the British Admiralty the importance of research in southern waters. In 1768, James Cook sailed under orders of the Admiralty to prosecute astronomical and geographical researches in the Southern Pacific. In July 1772, under similar orders, he set out to examine and determine once and for all the question of the supposed great southern continent. His vessel, the Resolution, accompanied by the Adventure, commanded by T. Furneaux, crossed the antarctic circle on Jan. 17 of the following year. This voyage, during which he thrice penetrated the antarctic, effectively disposed of the longcherished illusion. For it became evident that if such a continent existed it was frozen and uninhabitable. In addition, his explorations outlined the main features of the southern portions of the globe much as they remain to-day. Of further scientific interest is the fact that this voyage marked the conquest of scurvy. Cook lost but one man out of 118 on a voyage lasting 1000 days. For this service to hygiene, the Royal Society awarded him the Copley Medal in 1776 .

Jan. 17, 1839.-Balleny Islands.

John Balleny, in the schooner Eliza Scott, left Campbell Island, south of New Zealand, to search for new land. He reached the antarctic circle in $178^{\circ} \mathrm{E}$. on Jan. 29, but later, meeting heavy ice, turned west. wards and discovered the group of rocky $\cdot$ islands which bears his name. The islands were mapped and geological specimens collected. Balleny was sent out by the firm of Enderby Brothers, a London shipowning firm trading in seal oil. This firm showed a keen interest in geographical discovery, and one of the brothers was an original fellow of the Royal Geographical Society. They had previously, in 1830, dispatched John Biscoe on a two years' voyage combining sealing and exploration. Biscoe sailed through nearly fifty degrees of longitude south of the antarctic circle and discovered the coast of Enderby Land. He did not know of Bellingshausen's discoveries, but entered that sea and discovered Biscoe Islands and the coast of Graham Land.

\section{Jan. I8, r9r2.-The South Pole.}

Capt. R. F. Scott found the tent with the record that Roald Amundsen and four other Norwegians had reached the south pole on Dec. 16, 1911. Scott had reached the pole on the night of Jan. 17, but had realised from the tracks that his party had been forestalled. Scott and his companions, Wilson, Evans, Oates, and Bowers, set out on their tragic return journey. Evans fell ill and died, and the time involved in caring for their sick companion considerably delayed the party. A strong surface wind wiped out the track they were trying to follow; weather conditions were persistently adverse; the oil in the tins at the depots was insufficient, weather conditions having resulted in the perishing of the leather washers with consequent evaporation. Yet in spite of weariness and hunger, the party continued to the last to carry the geological specimens collected on the Beardmore glacier. The fossils in the specimens threw much light on the age and past history of this part of the antarctic continent; the gain to science was, however, obtained at the cost of heavy 